\title{
Analysis of Improvisation in Construction Through Agent-based Modelling
}

\author{
Hasnaa Alhussein ${ }^{\mathrm{a}}$, Farook Hamzeh ${ }^{\mathrm{b} *}$, AbdAllah Abou Yassin ${ }^{\mathrm{a}}$ \\ ${ }^{a}$ Graduate Student, American University of Beirut, Beirut 1107 2020, Lebanon \\ ${ }^{6 *}$ Assistant Professor, American University of Beirut, Beirut 1107 2020, Lebanon
}

\begin{abstract}
Improvisation is rational and decisive, deterministic and emergent, but impulsive and fuzzy. While the results of improvisation are perfectly understandable after the fact, the decision process is spontaneous in its making. Improvisational practices continue to exist within numerous construction operations where unforeseen uncertainty cannot be fully avoided. Therefore, a construction project will greatly benefit from applying an adaptive planning system that employs improvisation and hence reacts rapidly and wisely in case of unplanned or newly emerging problems. This study aims at developing a simulation model that depicts the improvisation process at the level of planners associated with different construction trades and identify different influencing factors. First, after attaining a thorough understanding of the process based on previous research studies, agent-based modelling is used to model the improvisation process that occurs at the level of each agent (planner), as well as the interaction processes that arise between the agents and the environment (construction project), and among the agents themselves. The simulation model takes into consideration several types of parameters that highly influence how each planner improvises. These parameters are planner-related, projectrelated, as well as problem-related. The contribution of this study lies in developing a better understanding of the improvisation mechanism within construction as well as identifying the impact of various types of influencing factors on the overall improvisation performance. Future research is recommended to better enhance the practices of improvisation for different construction projects.
\end{abstract}

(C) 2018 The Authors. Published by Diamond Congress Ltd., Budapest University of Technology and Economics Peer-review under responsibility of the scientific committee of the Creative Construction Conference 2018.

Keywords: improvisation; construction; agent; planners.

\section{Introduction}

Planning in construction is an indispensable process that spans throughout the project's life cycle and aims to achieve the project's objectives related to time, cost, quality, and safety. Planners and schedulers have always highlighted the importance of planning for organizing work, reducing risk, facilitating communication, maintaining good control, as well as reaching their desired objectives [1]. Unfortunately, traditional planning practices cannot develop plans and procedures for all possible scenarios and eventualities [2]. Therefore, improvisation may turn out to be the final resort for addressing the issues of uncertainty, dynamism, and complexity [3].

Improvisation has recently gained a wide interest in the field of organizations as it significantly contributes for better managing the problems of unforeseen uncertainty [4]. Numerous organizations have relied on improvisation to deal with unplanned interruptions and compensate for the limitations of traditional planning and improper management $[5,6]$. Therefore, understanding the dynamics of improvisation has become a necessity to survive in dynamic, complex, and/or uncertain organizational environments. Improvisation is the act of formulating a decision or performing an

*Corresponding Author: Farook Hamzeh, Email: fh35@mail.aub.edu 
action without having the optimal resources and/or information [7]. It helps decision-makers to make their decisions at the spot, without having the luxury of preparation [4]. Accordingly, researchers have demonstrated the practices of improvisation in different organizational settings and looked at different fields of application to analyze the process.

Due to their increasing levels of complexity, construction projects have been characterized with interdependent types of uncertainties $[8,9]$. Accordingly, one of the main issues that face planners in construction is the inability to stay on the right track during the construction phase due to uncertainty, improper planning, and unforeseen conditions. As a result, construction literature has introduced new procedures into planning to efficiently reduce the problems of uncertainty and variability. The Last Planner System (LPS) is developed to manage foreseen or expected uncertainties. It supports planning with greater detail as execution is approached so that constraints are removed prior to execution or construction [10]. However, a complex environment requires improvisation as a complementary practice for planning since it helps planners and decision-makers handle unplanned incidents which are unavoidable in any work environment $[4,7]$.

Improvisation in construction is an interesting practice to cater for the dynamism and the glitches resulting from unexpected uncertainty. However, few contributions are made in the literature to explain improvisation in the context of construction operations. The aim of this study is to better manage the unforeseen uncertainties in construction through analyzing the process of improvisation at the level of different planners within a certain construction endeavor and identifying the linkages between the overall improvisational outcomes and different project and planners-related factors. This research employs agent-based modeling to develop a simulation model that depicts the improvisational practices within a construction project. This paper entails a literature review of the improvisational practices in organizations and construction as well as background information about agent-based modelling. Then, the methodology of the study is explained, and the conceptual framework along with the agent-based model is presented. Finally, the paper encloses with a set of conclusions and future research works.

\section{Background}

\subsection{Improvisation in organizations}

Improvisation in organizations has been analyzed through looking at different perspectives. Innovation, creativity, and spontaneity have always accompanied the definitions of improvisational practices in organizations [11]. On the other hand, several researchers have looked at improvisation as a supportive practice that links between traditional plans and unforeseen situations [12]. Another approach for analyzing improvisation has focused on the method followed while improvising; improvisation is mainly re-combining the existing conditions, routines, and resources to manage unplanned situations [13]. In addition, as a general definition, improvisation is "the conception of action as it unfolds, by an organization or even one of its members, drawing on available material, cognitive, affective and social resources" [14].

Recent studies have considered improvisation as an essential performance variation that should be employed in rapidly changing and/or uncertain environments [4]. However, the possibility of generating accidents while improvising at operational work has been documented in the literature; hence, showing the need of advancing the knowledge of improvisation prior to start practicing [15]. Therefore, organizations have focused on analyzing the process of improvisation and studying its different influencing factors so that it's properly practiced. For instance, Trotter et al. (2014) have analyzed the application of Rasmussen's (1997) Risk Management Framework and Accimap methodology for identifying the influencing factors of improvisation in critical safety situations [16]. Moreover, some researchers have studied the appropriateness of improvisation for competing with other organizations through better responding to unexpected market conditions [17].

Different influencing factors of improvisation has proven to be crucial while analyzing or predicting the improvised outcome. These factors involve: experience, education, training to improvise, teamwork, collaboration, situation awareness, information flow, organizational structure, organizational memory, organizational culture, and authority mitigation [3, 18]. Besides of its influencing factors, improvisation has been described by a set of characteristics to assess its degree such as speed, novelty of input, and time pressure [3,6,14]. Also, the severity of improvisation has been portrayed as a continuum; it starts with interpretation, then proceeds to embellishment that's followed by variation, and finally ends up with improvisation [14]. 


\subsection{Improvisation in Construction}

Project control methods have gone through tremendous improvements with the aim of optimizing different performance indices, managing variability as well as catering for uncertainties. The Last Planner System is one of the control methods that intends to increase planning reliability and improve the project's overall performance by planning at different levels of detail during the construction phase. The LPS focuses on the quality criteria prior to execution of the tasks in order to avoid deviations resulting from uncertainty and/or improper planning [19].

Failures during construction have been classified into three categories [20]. The first category involves failures in executing planned tasks due to deficiencies in identifying constraints and removing them on time. The second category includes failures due to lack of proper planning and anticipation. Finally, the third group includes failures caused by uncertainties that cannot be foreseen or planned for. Construction planners are advised to enhance their improvisational skills for better managing the third category of failures [20].

A previous research study has modeled improvisation in construction as a decision making process and explained its different stages [21]. Also, another study has defined improvisation in construction as a deliberate decision-making process that is usually used when: 1) speed is required to meet a deadline, 2) planned procedures fail to meet the requirements, 3) pre-planned strategies fail to manage a sudden problem, and 4) standardized procedures fail to catch up with daily ameliorations and progress [22]. Statistical analyses of this study have highlighted the frequent types of problems initiating improvisation and showed the effect of some personal and organizational characteristics on the outcomes of improvisation. The study concluded that "failure in execution" and "seeing opportunities to improve ready and sound tasks" are the most frequent triggers of improvisation in construction. However, the degree of novelty along with the level of complexity are distinguished as criteria to assess the significance of the associated problems initiating improvisation. Moreover, the outcome of individual improvisation is measured through two outcome indices which are: the level of emerging waste and the task completion status. On the other hand, task completion represents the extent to which planner has completed or solved the task under consideration via improvisation [22].

Results of the study showed that personal traits such as high experience, reacting well to time pressure, taking risks, and communicating with others have a significant impact on the level of emerging waste and the task completion status when employing improvisation. Furthermore, Organizations that empower employees, keep good records, and give levels of authority to experienced employees in the field have higher chances of sound improvisations [22].

While causes and some influencing factors of improvisation in construction have been examined in previous study, the overall behavior of several improvisers working together on a single construction project hasn't been analyzed yet. Indeed, different improvisational capabilities of planners who work in different trades within a construction project, as well as the level of the unexpected uncertainty associated with that project highly influence the total improvisational outcome. This paper employs agent-based modeling for explaining the improvisational mechanism of a group of construction individuals working on certain construction project.

\subsection{Agent-based Modelling}

Modelling is the act of projecting or imagining a certain occurrence, situation, or incident in individual's mind and then formulating it explicitly [23]. For explaining and representing these models, different approaches are used such as mathematical modelling that leads to analytical solutions for the perceived models. Mathematical modelling is mostly pertained to models or systems of which components and relationships can be expressed through mathematical equations [24]. However, most of the real-life occurrences and social systems are very complicated so they require computer simulation to be analyzed instead of the analytical approaches. Simulation is "the process of designing a dynamic model of an actual dynamic system for the purpose either of understanding the behavior of the system or of evaluating various strategies for the operation of a system" [25]. Simulation is employed to mimic the operation of a real-life system by creating a simplified surrogate model representing that system. Systems are mainly simulated for measuring their performance, improving their operation, and/or testing the effect of a change or newly proposed practices [26].

Agent based modelling $(\mathrm{ABM})$ is a recent approach used to model complex systems for the purpose of understanding, explaining, or analyzing how they do work. "Agents" are considered the main constituents of these systems; they are autonomous and interacting among each other and with their environment. Agents can be people, time, space, asset, a controlling element, or even a collection of elements. A set of static and/or dynamic attributes usually distinguishes them. Dynamic attributes are deemed important during simulation since they change according to the agents' interactions. Agents with different dynamic attributes behave differently, however; the overall behavior 
of the system cannot be predicted. Hence, simulation is required to conclude the inclusive emergent behavior of the existing system [27]. On the other hand, static attributes are fixed and unchangeable during simulation. They are usually used to distinguish between different agents.

Numerous researches have used agent-based modeling to mimic different systems in various fields of application. This approach of modeling has been employed to analyze organizational behaviors, transportation, economic, social, ecological, and robotic systems [28]. In the field of construction, agent-based modeling has grabbed the interest of several researchers since construction operations are inherently complex and non-linear [29]. Also, modelers have always emphasized on enhancing the construction safety, and thus simulated several scenarios for that purpose. For instance, Palaniappan et al. (2007) has modeled the causes of accidents on construction sites and the interactions between different project factors, aiming to enhance the safety performance on sites [30].

This study adopts agent-based modeling to analyze the improvisational practices of different groups of improvisers within a construction project. The simulation model aims to explain how the improvisational process occurs at the level of each planner, and it tends to examine how different combinations of improvisers and project-related factors shape the overall improvisational performance.

\section{Methodology}

A stepwise research methodology is designed to reach the study's objective. First, the authors have conducted a review on previous studies that addressed the topic of improvisation so that different types and characteristics of improvisational practices occurring in different organizational settings are examined. Then, a review on major contributions that aim to manage uncertainty as well as make use of improvisation in the construction field is performed. Also, a previous exploratory study addressing improvisational practices in construction is examined so that necessary data analysis and statistical outcomes are assessed and considered to be used further in this study. As a result, research gaps have been identified, and the contribution of this study in enhancing the practices of improvisation in construction has been set accordingly.

Second, agent-based modeling is used to mimic the behaviors of the improvisers. A conceptual model is developed while identifying the main environment, agents, influencing factors and parameters, as well as agents' behaviors and interactions. Building the components of the model is mainly based on the statistical findings of a previous research study as well as the available literature. Modeling the improvisation process could be considered as continuous loop that any construction individual could pass through. This loop starts with a problem causing improvisation and accordingly initiating the interaction between improvisers and the surrounding environment; this interaction is modeled using ABM. Then, agents improvise by passing through a well-defined process where behaviors and rules of interactions are set. Finally, the improvised solution is reached, and the level of success is determined accordingly; this is also modeled using ABM.

\section{Agent-Based Modeling}

\subsection{Conceptual Framework}

A conceptual framework is developed for elucidating the process of improvisation at the level of different individuals working together and interacting with one another within the same construction project. Also, this framework aims at depicting the impact of different improviser and project-related factors on the overall improvisational performance. The contribution of the developed conceptual model lies in providing a better understanding of the dynamics of the improvisational practices within a group of construction individuals as well as guiding construction professionals and planners to properly practice improvisation and make use of it under unexpected or unplanned conditions.

Similar to any organizational setting, improvisation in construction is usually observed in case of emergent, unplanned, and/or unexpected situations. Individuals who are in charge of executing, supervising, or planning for construction tasks are those who may face unexpected or unplanned work and eventually may end up improvising to solve the problem in hand. In other words, improvisation in construction occurs while individuals are trying to execute a certain task or endeavour. In this study, those individuals are called "planners" since they always have to plan even if they execute or supervise the work. Therefore, in this context, planners are potential improvisers. In case they decide to improvise, they will either succeed to solve the problem under consideration or not, depending on different influencing factors which are addressed in this framework. 
Different types of influencing factors significantly affect the way individuals improvise in construction and accordingly shape their improvisational outcomes. Construction planners usually improvise as they have to take decisions or actions swiftly in order to cope with an unplanned or unexpected event or situation. However, problems initiating improvisation are different in nature so that they require varying levels of improvisational efforts to be resolved. According to a previous research study, causes of improvisation are most likely to be: 1) missing prerequisites, 2) inadequate definition of task, 3) opportunities to improve sound tasks, and/or 4) new circumstances during execution [22]. However, each kind of these problems is characterized by certain criteria that determine the extent of improvisational significance. These problem-related factors should be considered to analyze the process of improvisation rather than exploring different kinds of problems. The level of complexity and the degree of novelty are significant parameters to identify the required degree of improvisation and accordingly classify problems based on their improvisational requirements [22]. However, in the context of construction, there are other problem-related factors which can influence individual improvisational practices such as the number of trades on which the problems depend and the availability of the time duration to solve each problem. The following table provides definitions for problem-related factors, each of which can highly impact one's improvisational outcomes in construction.

Table 1- Problem-related factors

\begin{tabular}{ll}
\hline Problem-related factors & Definition \\
\hline Level of complexity & $\begin{array}{l}\text { Extent to which the goals associated with a given problem are undefined or } \\
\text { unclear, and the degree to which the required methods to resolve the problem via } \\
\text { improvisation are complex or hard. }\end{array}$ \\
\hline Degree of novelty & Degree to which the problem in hands is totally new and novel \\
\hline Trade interdependence & Number of trades on which the problem relies on \\
\hline Time Availability & Available time to generate an action or decision in order to resolve the problem \\
\hline
\end{tabular}

On the other hand, improvisers have varying levels of personal criteria that highly shape their improvisational practices and accordingly influence their improvisational decisions or actions. For the same problem initiating improvisation, improvisers are expected to end up with different outcomes depending on their personal traits. Previous statistical analyses and hypotheses testing show that work experience, reacting well to time pressure, taking risk, and ability to communicate with others are significant influencing factors while studying improvisation in construction [22]. Also, the trade to which an improviser belong significantly shapes his/her improvisational process or mechanism. Another type of influencing factors is related to the project itself. The level of unforeseen uncertainty determines the extent to which improvisation is required in a certain project. In this framework, the level of uncertainty is modeled as a distribution of different types of problems initiating improvisation; these problems impose varying levels of improvisational efforts. Moreover, the distribution of improvisers among the trades as well as the way problems initiating improvisation are dispersed among the trades highly impact the overall improvisational performance in the project.

After identifying each of the problem, improviser, and project-related factors, construction planners will pass through the improvisation process and end up with a certain improvised decision or action. The success or the rightness of the improvised outcome is measured in this model through two outcome indices: 1) Level of emergent waste: how much waste is produced due to improvisation, and 2) Task completion status: how much the improvised decision or action has completed the task in hands or solved the problem. Therefore, improvisers might end up with one of the following outcomes: 1) Task completion without waste, 3) Task completion with waste, and 3) Task incompletion.

Note that improvisational experience is an essential parameter that affects the behaviors of improvisers with time. Initially, each improviser has a certain initial improvisational experience depending on his personal criteria. However, this initial experience won't be constant as improvisers are experiencing new improvisational instances as well as interacting with other improvisers within the same project. Therefore, the initial experience of improvisers will increase with time differently as they pass through different improvisational tasks. Moreover, it will also increase due to the interaction and learning effect among improvisers who belong to the same trade.

\subsection{Results and Discussion}

After developing a conceptual framework related to improvisation in construction, an agent-based model is built up through first identifying its component, then recognizing the linkages among these components. Fig. 1 explains the 
rationale of the agent-based model. First, the environment is the construction project during which all construction planners belonging to different trades work and interact together. Second, problems initiating improvisation have different parameters such as level of complexity, degree of novelty, trade interdependence, and time availability. These problems are created as events in the environment so that improvisation is initiated at the level of different planner. As the problem reaches an improviser who is the main agent in the model, personal influencing factors shape the improvised outcome which is based on two outcome indices: 1) level of waste, and 2) task completion status.

Environment: Construction Project

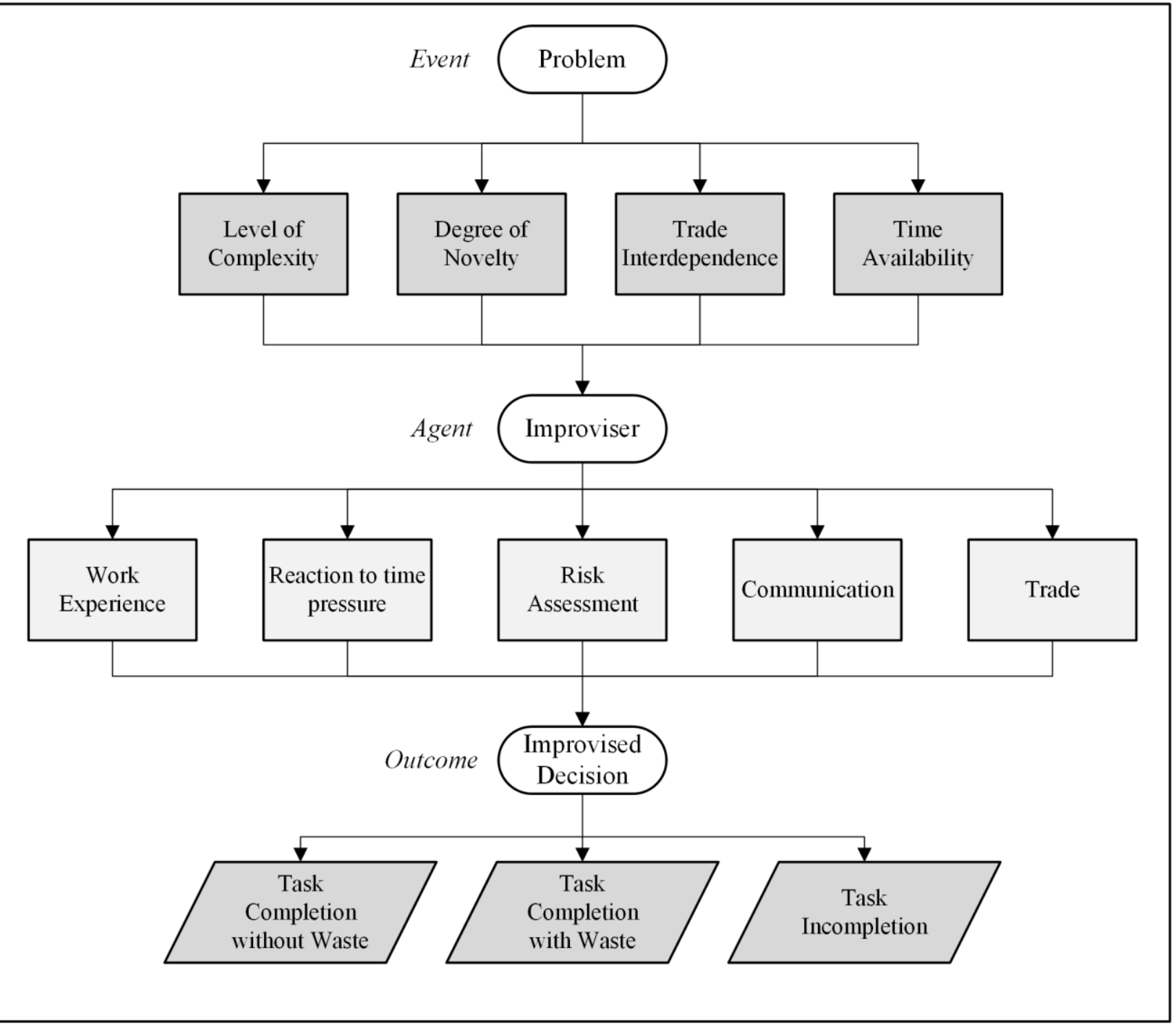

Fig.1. Agent-based Model

\section{Conclusions and Future Work}

Construction planning is deemed a crucial practice that aims to translate the project's goals into executable plans. However, one of the main issues that face planners and schedulers is the inability to stay on the pre-planned track during the construction phase. In some cases, such planning failures can be attributed to improper or even insufficient planning practices. However, failing to achieve the prearranged plans is often provoked by unforeseen or uncertain conditions, which are deemed companions to any construction project. Planners have tried hard to manage uncertainties in construction; however, unexpected uncertainties continue to exist during execution. Therefore, improvised solutions 
are usually required under such situations for maintaining full control on construction processes and reducing the potential induced losses and delays. Unfortunately, very few researches have tried to enhance the understanding of improvisation in construction, though it is an unavoidable practice in numerous construction operations.

Modeling the improvisation process could be seen as a continuous loop that any construction planner could pass through. As a rule, the loop starts with a problem from a given environment and the corresponding interaction that would occur due to this problem between the agent and the environment (modeled using Agent Based Modeling), followed with a solution generation process to reach the improvised decision, during the solution generation process different interactions would occur between different agents (modeled using Agent Based Modeling), finally an attempt to implement the solution by improviser is done and the level of success is determined accordingly ( modeled using Agent Based Modeling).

Improvisation is a topic that is being addressed by several studies; some studies define it while others describe it. This paper sets the premise for modeling the improvisation process and thus offers the ability to measure the performance of improvisers as well as the impact of improvisation on the planning and construction process. Therefore, proper proactive actions could be taken to optimize the improvisation process in construction. Besides, defining and modeling different attributes which construction planners would provide the capability of better understanding the mechanism that each improviser can follow.

To achieve the above-mentioned goals, further research work is required to perform the following: 1) Quantifying the defined attributes and provide a weighing factor for each one, and 2) Gathering data corresponding to different cases from the construction industry in which failure occur and use them as input, 3) Running the simulation model for several cases, and 4) Measuring the influence of variation of personal and project-related factors on the improvised outcomes.

\section{References}

[1] G. Akrani, Importance of Planning - Why Planning is Important? Available from: http://kalyan-city.blogspot.com/2012/02/importance-ofplanning-why-planning-is.html, 2012., [Accessed: Mar.17, 2015].

[2] D.D. Woods, E. Hollnagel, Prologue: resilience engineering concepts, in: E. Hollnagel, D.D. Woods, N. Leveson (Eds.), Resilience engineering: concepts and precepts, Ashgate, 2006, pp. 1-8.

[3] M. J.Trotter, P. M. Salmon, M. G. Lenné, Improvisation: theory, measures and known influencing factors, Theoretical Issues in Ergonomics Science, (2013), 14(5) 475-498.

[4] A. L Hadida, W. Tarvainen, J. Rose, Organizational improvisation: A consolidating review and framework, International Journal of Management Reviews, (2015), 17(4) 437-459.

[5] D. J. Mendonca, W. A. Wallace, A Cognitive Model of Improvisation in Emergency Management, IEEE Transactions on Systems, Man, and Cybernetics - Part A: Systems and Humans, (2007), 37(4) 547-561.

[6] C. Chelariu, W. J. Johnston, L. Young, Learning to improvise, improvising to learn: A process of responding to complex environments, Journal of Business Research, (2002), 55(2) 141-147.

[7] C. U. Ciborra, Notes on improvisation and time in organizations, Accounting, Management and Information Technologies, (1999), 9(2) 77-94.

[8] C. Fang, F. Marle, E. Zio, J.C. Bocquet, Network theory-based analysis of risk interactions in large engineering projects, Reliability Engineering \& System Safety, 106(2012), 1-10.

[9] F. Marle, A structured process to managing complex interactions between project risks, International Journal of Project Organization and Management, (2015), 6(1-2) 4-32.

[10] F. Hamzeh, E. Zankoul, C. Rouhana, How can 'tasks made ready' during lookahead planning impact reliable workflow and project duration? Construction Management and Economics, (2015), 33(4) 243-258.

[11] M. Magni, L. Proserpio, M. Hoegl, B. Provera, The role of team behavioral integration and cohesion in shaping individual improvisation, Research Policy, (2009), 38(6), 1044-1053.

[12] M. M. Crossan, H. W. Lane, R. E. White, L. Klus, The improvising organization: Where planning meets opportunity, Organizational Dynamics, (1996), 24(4) 20-35.

[13] S. Leybourne, Managing change by abandoning planning and embracing improvisation, Journal of General Management, 31(2006).

[14] M. P. Cunha, J. V. Cunha, K. Kamoche, Organizational Improvisation: What, When, How and Why, International Journal of Management Reviews, (1999), 1(3) 299-341.

[15] A. G. Amorim, C. M. N. A Pereira, Improvisation at Workplace and Accident Causation - An Exploratory Study, Procedia Manufacturing, 3(2015), 1804-1811.

[16] M. J. Trotter, P. M. Salmon, M. G. Lenné, Impromaps: Applying Rasmussen's Risk Management Framework to improvisation incidents, Safety Science, 64(2014), 60-70.

[17] M. P. Cunha, S. R. Clegg, K. Kamoche, Improvisation as "real time foresight”, Futures, (2012), 44(3) 265-272.

[18] F. Størseth, R.K. Tinmannsvik, K. Øien, Building safety by resilient organization - a case specific approach, in: R. Bris, C.G. Soares, S. Martorell, (Eds.), Reliability, risk, and safety: theory and applications, London: Taylor \& Francis, 2010, 1209-1214.

[19] H. G. Ballard, The last planner system of production control, University of Birmingham, 2000. 
[20] F.R. Hamzeh, F. Abi Morshed, H. Jalwan, I. Saab, Is Improvisation Compatible with Lookahead Planning? An Exploratory Study, in: 20th Conference of the International Group for Lean Construction, San Diego, 2012, 441- 450.

[21] F.R. Hamzeh, H. Al Hussein, F. Faek, Modelling Improvisation in Construction as a Decision-Making Process, Journal of Management in Engineering, ASCE, 2018, accepted. In process.

[22] F.R. Hamzeh, F. Faek, H. Al Hussein, Understanding Improvisation in Construction: Causes, Behaviors, and Consequences, Construction Management and Economics Journal, 2018, accepted. In process.

[23] J. M. Epstein, Why Model? Journal of Artificial Societies and Social Simulation, 2008, 11(2).

[24] A. Law, Simulation Modeling and Analysis (5th Eds.), McGraw Hill Education, 2014.

[25] R. Ingalls, Introduction to Simulation: Introduction to Simulation, Winter Simulation Conference, 2002.

[26] W.D. Kelton, R. P. Sadowski, N. B. Swets, Simulation with Arena (5th Eds.), New York: McGraw Hill, 2010.

[27] C. M. Macal, M. J. North, Tutorial on Agent-based Modeling and Simulation, Journal of Simulation, 4 (2010), 151-162.

[28] P. Davidsson, J. Holmgren, H. Kyhlbäck, D. Mengistu, M. Persson, Applications of Based Simulation, in: the 7th International Workshop on Multi-Agent-Based Simulation, Hakodate, Japan, 2006.

[29] N. Gilbert, K. Troitzsch, Simulation for the Social Scientist, McGraw-HillEducation, UK, 2005.

[30] S. Palaniappan, A. Sawhney, M.A. Janssen, K.D. Walsh, Modeling construction safety as an agent-based emergency phenomenon, 24th International Symposium on Automation \& Robotics in Construction, Construction Automation Group, 2004, 375-382. 